\title{
DIVERSIDADE TAXONÔMICA E PADRÕES DE DISTRIBUIÇĀO GEOGRĀFICA EM PICRAMNIA (SIMAROUBACEAE) NO BRASIL
}

José Rubens Pirani ${ }^{1}$

RESUMO - O gênero neotropical Picramnio Sw., tem 19 espécies no Brasil, das quais 12 são exclusivamente brasileiras. Os principais padrões de variação e distribuiç̧ões geográfica e ecológica desses taxa, permitem o reconhecimento de algumas categorias de espécies: espécies monotípicas taxonomicamente isoladas, pares ou grupos de espécies muito relacionadas, espécies politípicas e complexo de espécies.

Três principais padrões de distribuição geográfica das espécies brasileiras são apresentados: amplamente distribuídas; distribuição restrita; distribuição muito restrita.

Com base na biogeografia, 5 "regiões" com diferentes agrupamentos de taxa foram reconhecidos: Amazonia (8 spp.); Nordeste e Brasil Central (6 spp.); região costeira da Paraíba até Alagoas (5 spp.); região Leste da Bahia até São Paulo (7 spp.) e Sudeste do Brasil (4 spp.). Os maiores centros de diversidade genética do gênero estão na Amazônia e na Floresta Atlântica.

Mapas com as distribuições conhecidas das espécies são apresentados e discutidos.

Palavras-chave: Picramnia, Simaroubaceoe, neotropical, distribuição geográfica.

\begin{abstract}
In the neotropical genus Picramnia Sw., 19 species have been recognized for Brazil, from which 12 are exclusively brazilian. The main patterns of variation and geographical and ecological distribution of those taxa led to the recognizition of several categories of species: monotypic taxonomically isolated species, closely related pairs or groups of species, polytypic species and complex species.

Three main patterns of geographic distribution of the brazilian species are proposed and discussed: 1 . Wide range (with 3 areas, 3 spp.); 2 . Restrict range (with 4 areas, 8 sub-areas, 13 spp.); 3 . Very restrict range (with 3 areas, 3 spp.).
\end{abstract}

1 - Departamento de Botânica; Instituto de Biociências, Universidade de São Paulo. 
On a biogeographical basis, 5 "regions" with different groupments of taxa have been recognized: Amazon ( $8 \mathrm{spp}$.), Central and Northeastern Brazil (6 spp.), coastal region of Paraíba ( $7 \mathrm{spp}$.), and Southern Brazil (4 spp.) The major centers of genetic diversity of the genus in Brazil are the Amazon and the Atlantic Forest. Maps depicting the known distribution of the species discussed are presented.

Key-words: Picramnia, Simaroubaceoe, neotropical, distribution patterns.

\section{Introdução}

Picramia Swartz é um gênero neotropical, com aproximadamente 40 espécies distribuídas da Flórida (Estados Unidos), Antilhas e sul do México até a América do Sul, onde está ausente apenas no Chile, embora na Argentina não ocorra abaixo de $30^{\circ} \mathrm{S}$ (Mapa 1). A presença de $P$. sellowii no Uruguai é referida por um só autor (Lombardo 1964), e ainda não foi confirmada.

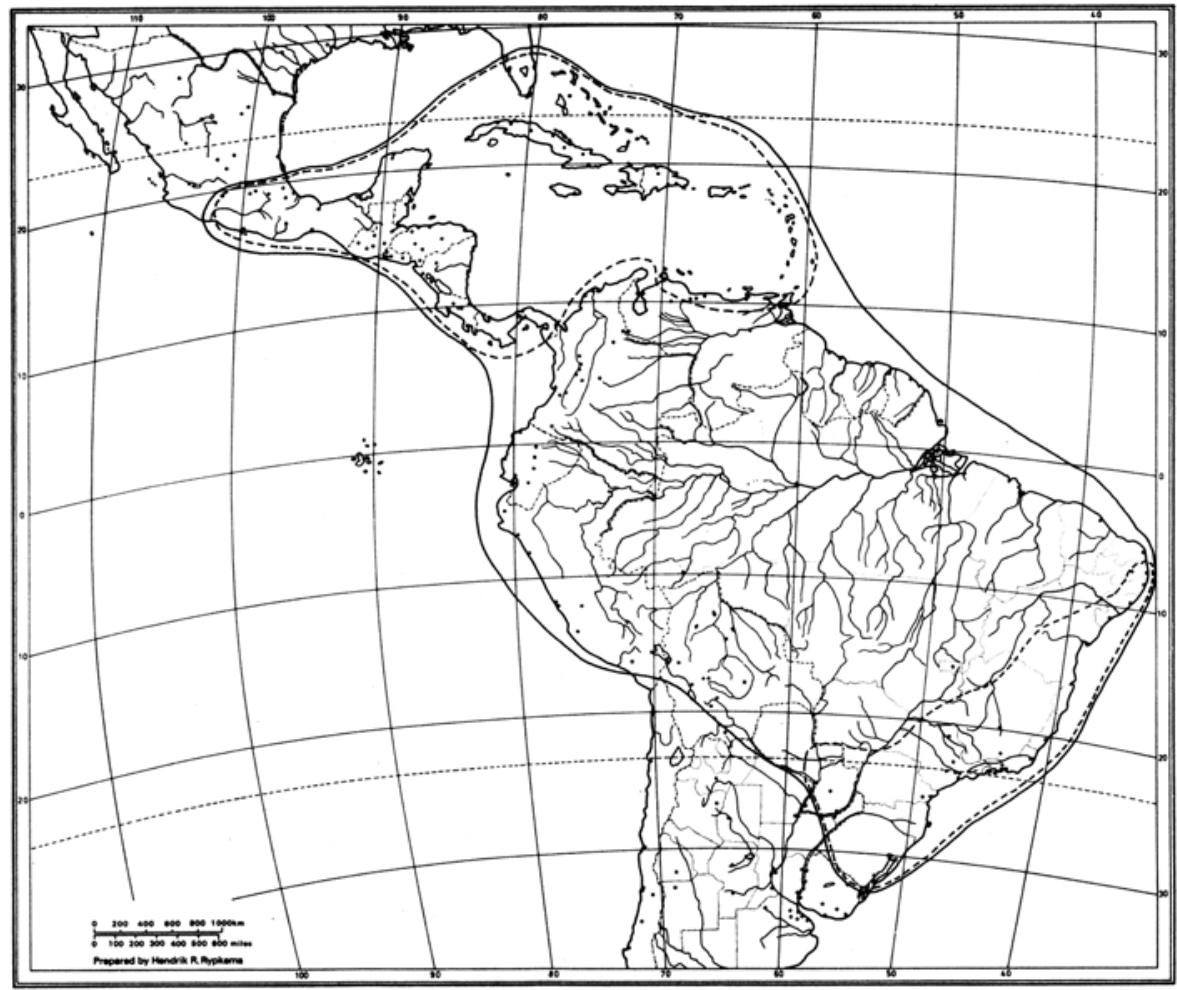

Mapa 1 - Distribuição geográfica do gênero Picramnia: a linha contínua denota a área total; a linha tracejada indica a distribuição das espécies com flores consistentemente trímeras. 
Único gênero da subfamília Picramnioideae (segundo a classificação de Engler 1931 e Scholz 1964), Picramnia é bem distinto na família Simaroubaceae pelo seguinte conjunto de caracteres: folhas pinadas com folíolos bem articulados na base, mais ou menos assimétricos; inflorescências em tirsos ramosos portando diminutas flores isoladas ou mais freqüentemente glomeruladas, trímeras a pentâmeras (raro hexâmeras), díclinas (em plantas dióicas), com estames opostos às pétalas e gineceu sincárpico bi a tricarpelar; fruto baga de coloração viva. A maioria das espécies são arvoretas ou arbustos do interior de florestas, embora algumas tenham conquistado ambientes abertos ou rupestres.

Desde a monografia de Engler (1874), não foi feito um tratamento abrangente deste gênero, e o seu conhecimento tem-se desenvolvido basicamente através de contribuições ao nível de floras locais ou regionais, com várias espécies novas descritas recentemente (Pirani 1988, Pirani \& Thomas 1988, Thomas 1988).

O centro de diversidade genética do gênero ocupa o norte da América do Sul, incluindo a região andina com sua topografia acidentada, e o platô e pla nície amazônicos. Esta área abriga pelo menos 20 espécies, algumas delas amplamente dispersas, outras de distribuição restrita.

$\mathrm{Na}$ América Central e sul do México, foram recentemente reconhecidas 12 espécies (Thomas 1988): $P$. antidesma Sw. com 3 subespécies, $P$. deflexa $\mathrm{W}$. Thomas, $P$. gracilis Tul., $P$. guerrerensis W. Thomas, $P$. hirsuta W. Thomas, $P$. latifolia Tul., $P$. matudai Lundell, $P$. pentandra Sw., $P$. polyantha (Benth.) Planch., $P$. sphaerocarpa Planch., $P$. teapensis Tul. e $P$. xalapensis Planch. Destas, a única que ocorre também no Brasil é $P$. latifolia.

No Brasil, reconhecemos agora 19 espécies, das quais 12 são exclusivamente brasileiras (Pirani 1989; Pirani 1990). Falta ainda um estudo das espécies dos demais países da América do Sul, também ricos em espécies, inclusive endêmicas, como $P$. nuriensis Steyermark (Venezuela) e $P$. monniniifolia Rusby (Bolívia). Só então um delineamento completo dos centros de diversidade e padrões de distribuição no gênero será alcançado. Entretanto, como os dados já disponíveis representam o conhecimento global da maioria das espécies do gênero, algumas conjecturas podem ser desenvolvidas, principalmente com referência aos táxons brasileiros.

\section{Metodologia}

As análises de padrões de distribuição geográfica das espécies de Picramnia do Brasil basearam-se nos dados do tratamento taxonômico de Pirani (1989), obtidos do estudo das coleções dos seguintes herbários: A, AAU, ALCB, B, BHCB, BHMH, BM, C, CAY, CEPEC, CH, COL, CTES, F, FLOR, G, GH, GUA, HAMAB, HB, HBR, HRB, HRCB, IAN, IBGE, ICN, INPA, IPA, JPB, 
K, L, LE, LIL, LP, MAC, MBM, MG, MICH, MO, NY, P, PACA, R, RB, RFA, S, SP, SPF, SPSF, U, UB, UC, UEC, UFGO, US e VEN.

\section{Distribuição de Picramnia no Brasil}

Os padrões de distribuição que podem ser distintos para as espécies brasileiras são apresentados na Tabela 1, embora as bases da diferenciação dos mesmos sejam relativamente arbitrárias. Três espécies são amplamente dispersas (Padrão 1); destas, duas têm uma amplitude ecológica grande ( $P$. sellowii Planch. com duas subespécies relativamente bem caracterizadas ecologicamente, e $P$. latifolia Tul.) e são de resto as duas espécies de maior distribuição de todo o gênero; a terceira, $P$. ramiflora Planch., ocorre do Ceará até Santa Catarina, predominantemente nas florestas da costa, mas penetrando até o interior em Minas Gerais e Mato Grosso do Sul (ver também Mapas 2 e 3).

Na categoria de "distribuição restrita" (padrão 2, tab. 1) foram incluídas espécies com áreas de ocorrência mais limitadas e que aparentemente demonstram preferências de habitat mais estreitas, não sendo possível avaliar no momento até que ponto sua distribuição esteja limitada por restrições de dispersão. Encontramos aqui espécies dispersas em 4 grandes regiões: Amazônia, Leste, Sul e centro do Brasil. Na região basicamente amazônica (I) há 4 áreas de distribuição:

a) centrada no noroeste da América do Sul e oeste da Amazônia, com $P$. caracasana Engl. (Mapa 4); é interessante notar aqui que a presença desta espécie no Brasil restrita à área de Santo Antônio do Içá e São Paulo de Olivença (AM) coincide com território proposto por Prance (1982a) como "refúgio", rico em endemismos de angiospermas.

b) distribuição centrada no oeste da Amazônia e Andes orientais, com $P$. magnifolia Macbr. e P. juniniana Macbr. (Mapa 5), ambas de notória preferência pelas florestas-de-terra-firme mas freqüentes também em florestas de várzea e em florestas submontanas e montanas até cerca de 1000 a $2000 \mathrm{~m}$.

c) distribuição centrada nas Guianas e Amazônia oriental, com P. guianensis (Aubl.) Jansen-Jacobs, associada preferencialmente a solos ricos em bauxita (Mapa 4).

d) distribuição centrada no centro-sul da Amazônia brasileira, com $P$. elliptica Pirani \& Thomas, que se estende através de florestas-de-galeria até áreas dominadas por cerrados no Mato Grosso (Mapa 6).

E importante salientar que as três últimas áreas (b, c, d) coincidem com as zonas florísticas da Hiléia amazônica distintas por Ducke \& Black (1953).

$\mathrm{Na}$ região compreendida pelo Leste do Brasil (II, tab. 1) incluem-se 5 espécies, quatro de flores trímeras e uma pentâmera. Nesta última, $P$. gardneri Planch., distinguimos 2 subespécies: subsp. gardneri, do Espírito Santo e Minas Gerais ao sul de São Paulo, e subsp. septentrionalis Pirani, restrita à flo- 


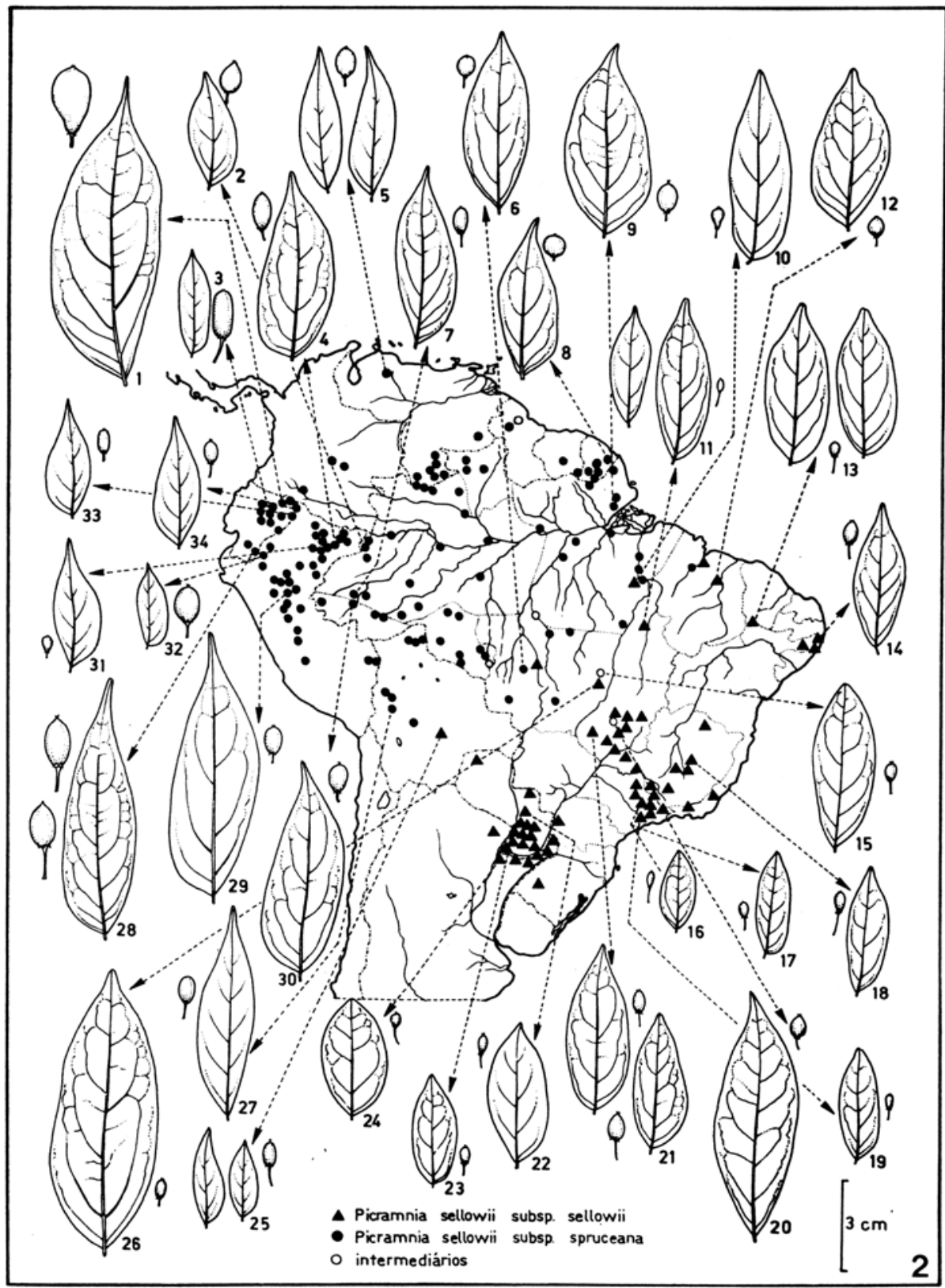

Mapa 2 - Distribuição geográfica de Picramnia sellowii Planch., discriminando as 2 subespécies, espécimes intermediários entre elas, e variação morfológica de folíolos laterais distais e frutos. 


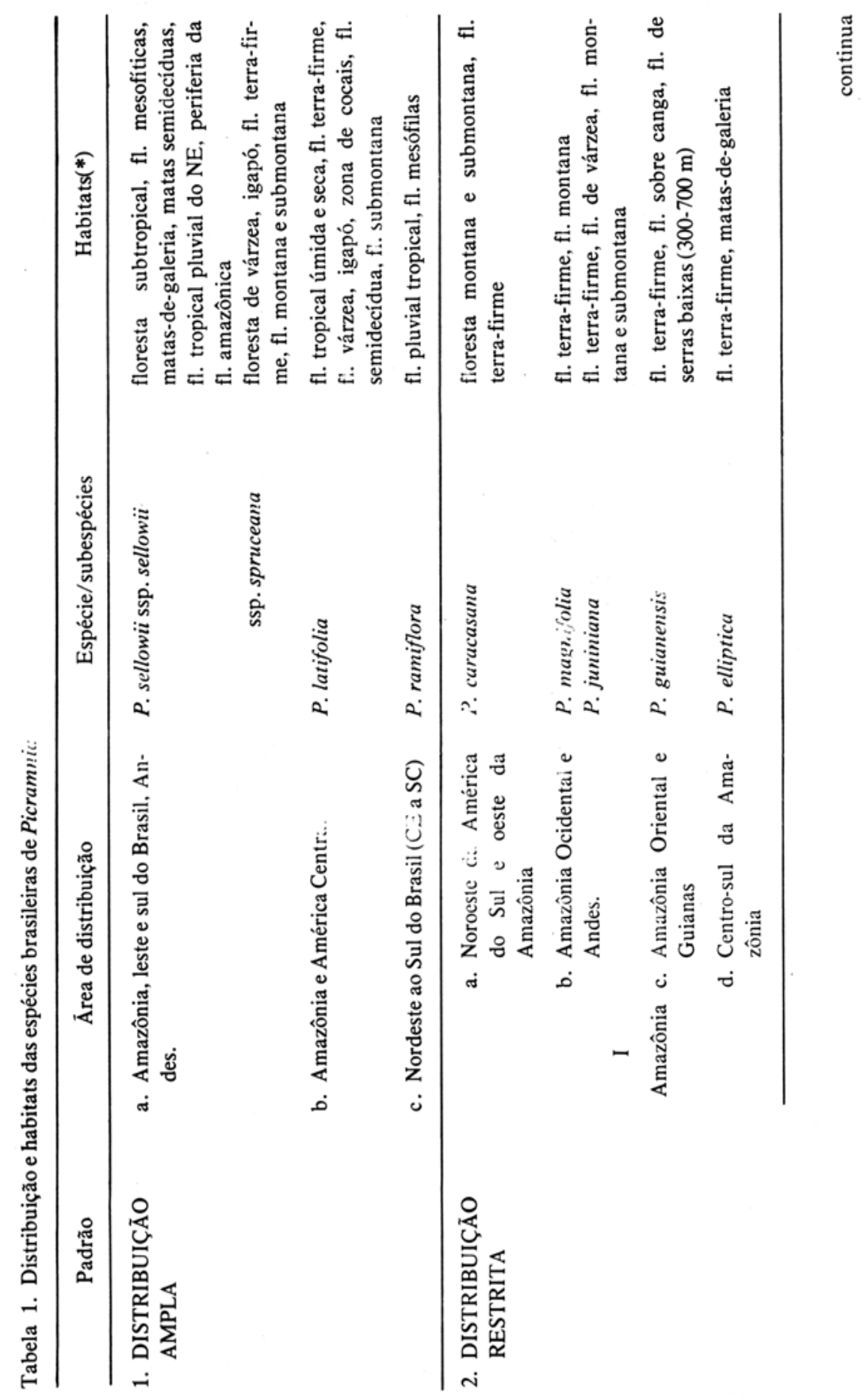




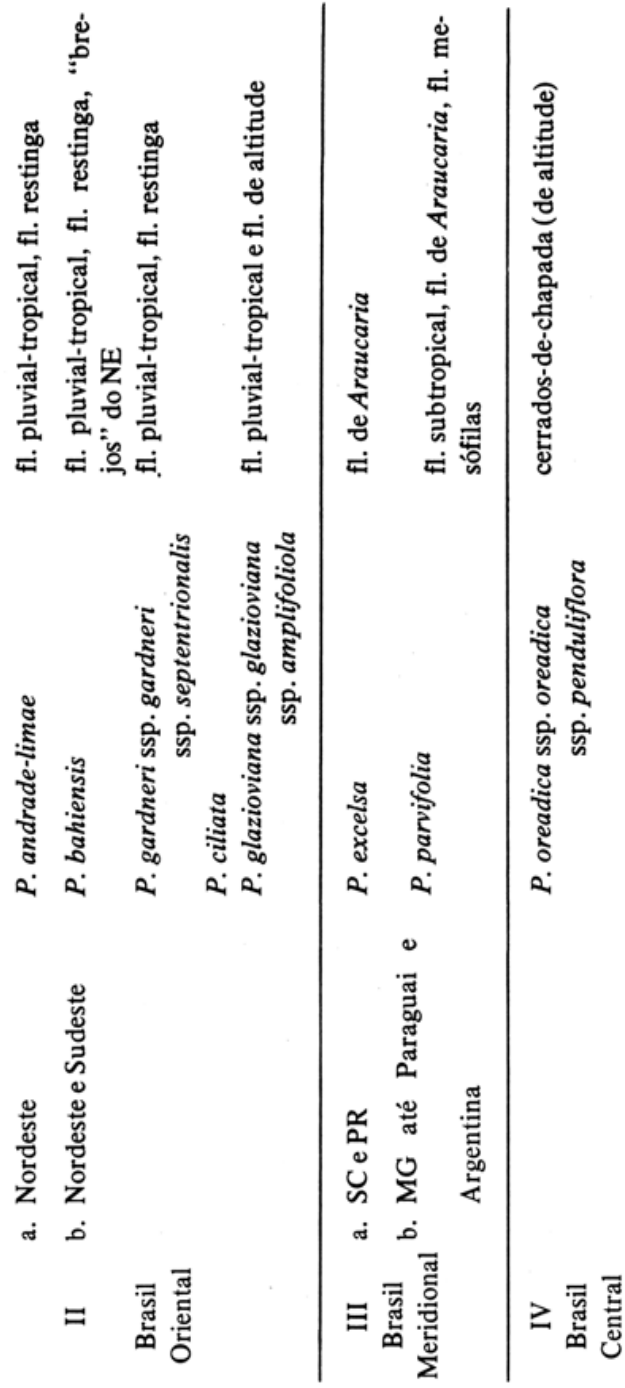

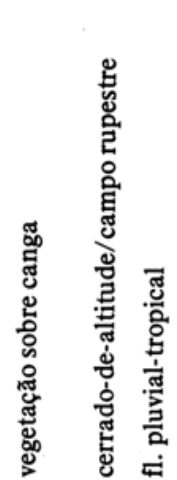

䓪

范泀

융

电

音

ชั ซึ

安 欲

范

u

芩

땐

苋 통

วิ

응음

요

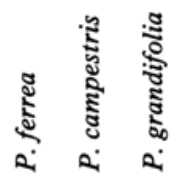

ก.

氖

\&

สั้ ลิ

-

হิ ป্ّ

의

তิ

氙

ผ ํํํ

붕

필

끈

옹

은

氠 종

ชิ

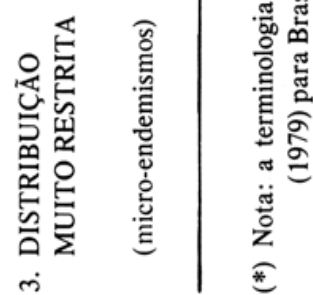




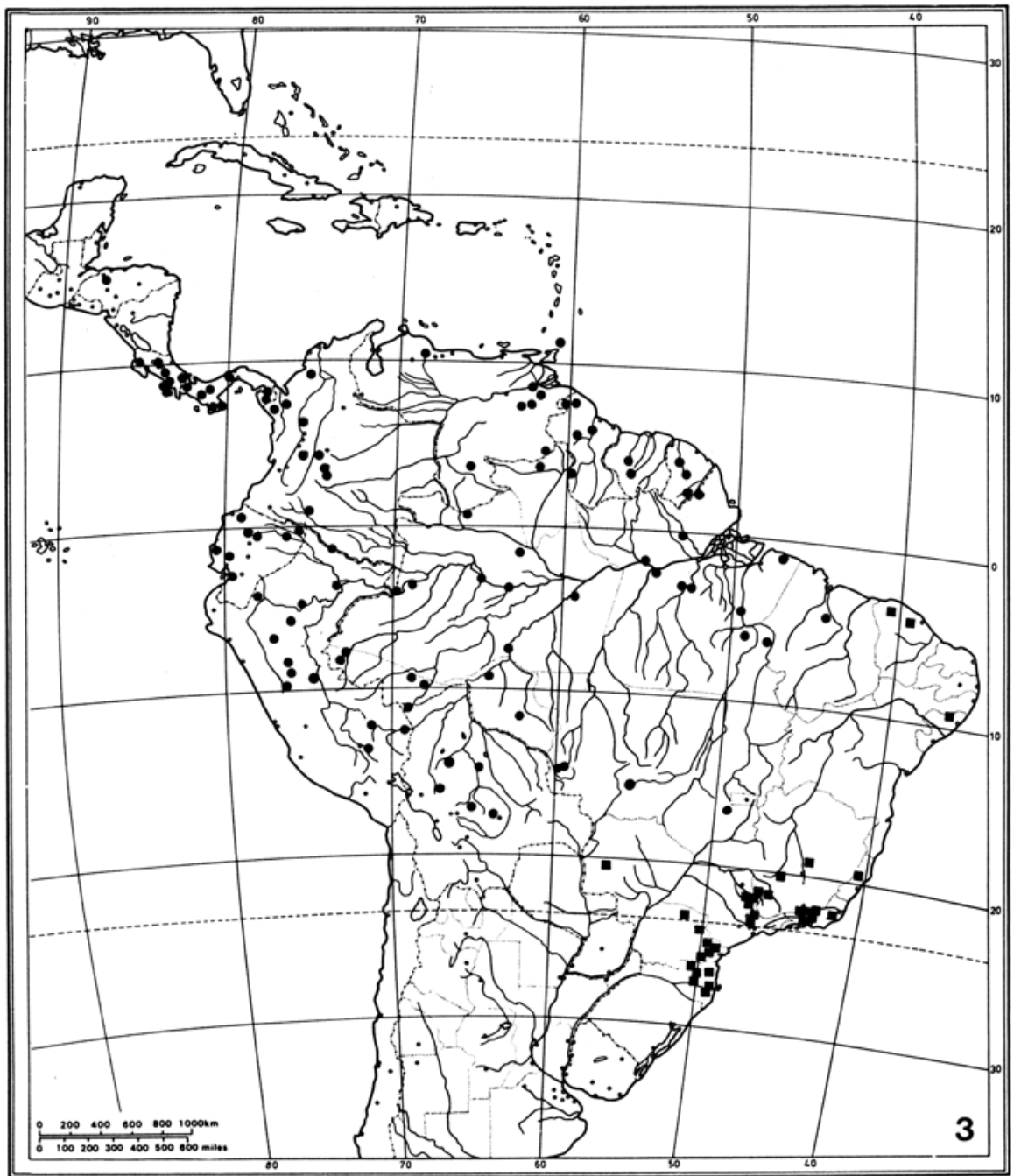

Mapa 3 - Distribuição geográfica de Picramnia latifolia Tul. (círculos) e $P$. ramiflora Planch. (quadrados). 


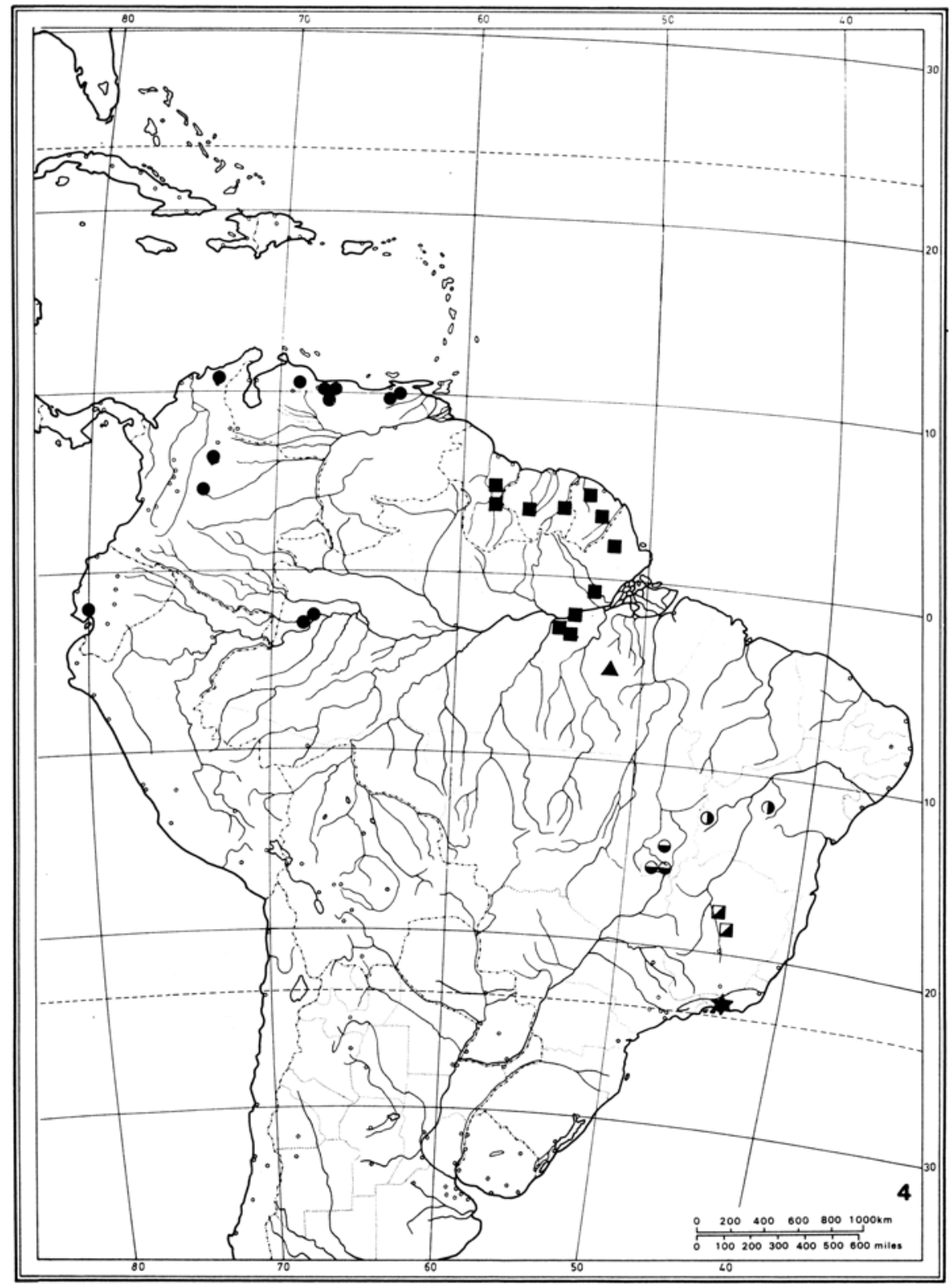

Mapa 4 - Distribuição geográfica de Picramnia caracasana Engl. (círculos pretos); $P$. guianensis (Aubl.) Jansen-Jacobs (quadrados pretos), P. ferrea Pirani \& Thomas (triângullo); $P$. oreadica Pirani subsp. oreadica (círculos semi-preenchidos na base) e subsp. penduliflora Pirani (círculos semi-preenchidos à direita); P. campestris Rizz. \& Occh. (quadrado semi-preenchido), e $P$. grandifolia Engl. (estrela). 


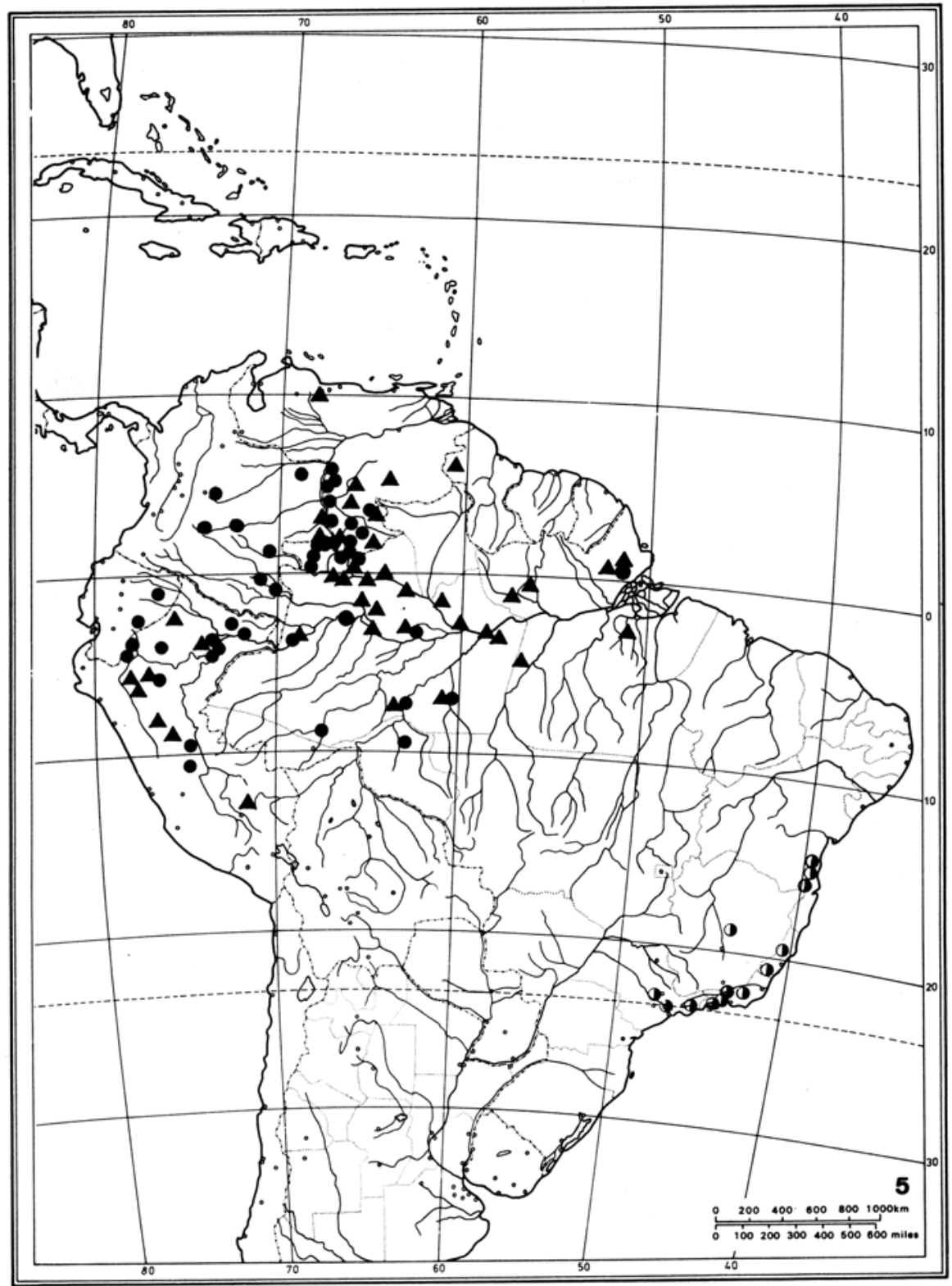

Mapa 5 - Distribuição geográfica de Picramnia magnifolia Macb. (círculos pretos). $P$. juniniana Macbr. (triângulos) e $P$. ciliata Mart. (círculos semi-preenchidos). 


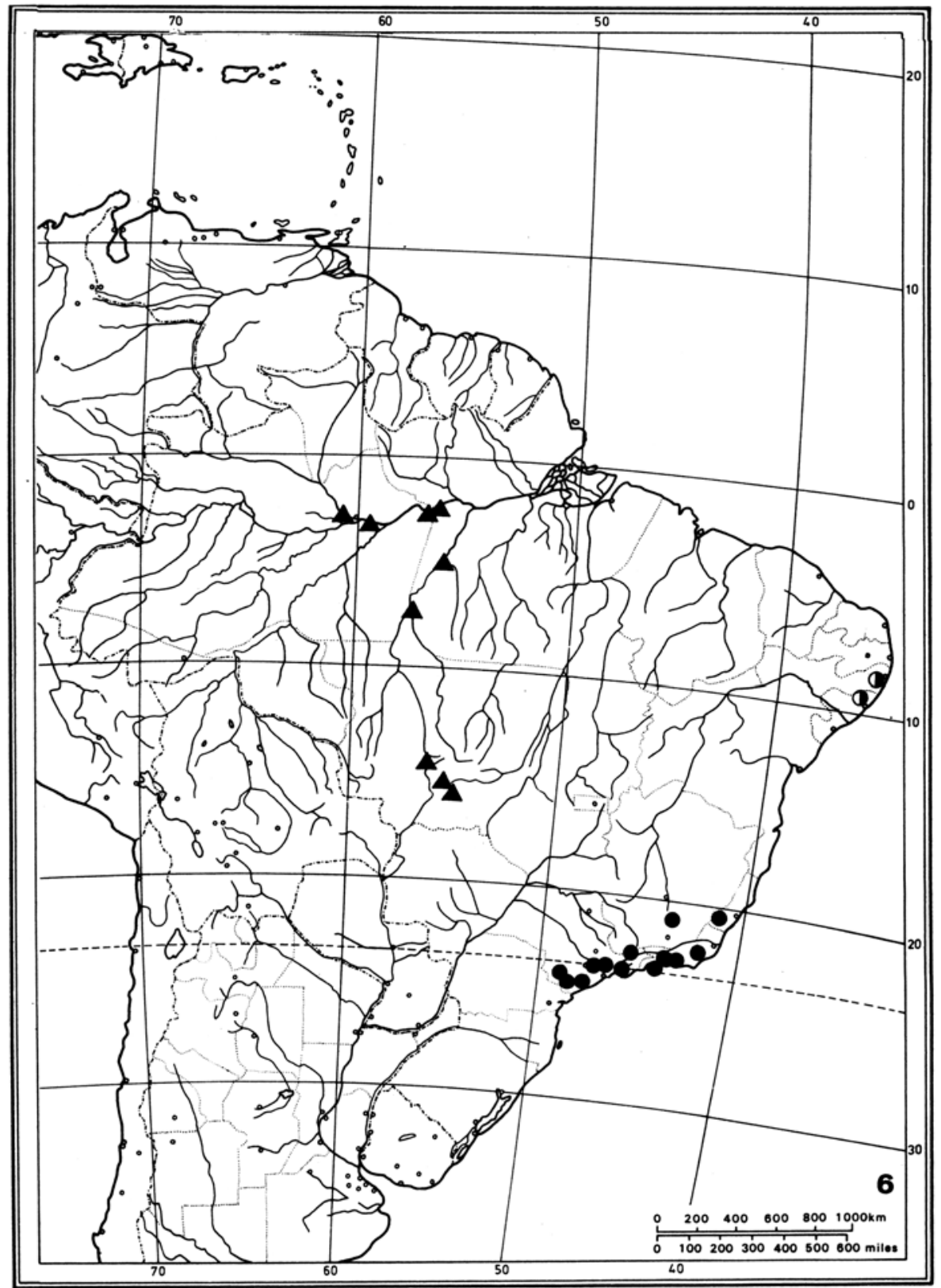

Mapa 6 - Distribuição geográfica de Picramnia elliptica Kuhlmann ex Pirani \& Thomas; P. gardneri Planch. subsp. gardneri (círculos pretos) e subsp. septentrionalis Pirani (círculos semipreenchidos). 
resta costeira de Alagoas e Pernambuco (Mapa 6). Uma disjunção mais ou menos semelhante a esta é observada em $P$. glazioviana Engl., que também possui uma subespécie no litoral de Pernambuco e Alagoas (subsp. amplifoliola Pirani), enquanto a subsp. glazioviana ocorre da Bahia até São Paulo nas florestas úmidas do litoral e também em florestas serranas no interior de Minas Gerais (v. Mapa 7). Ocupando aproximadamente a mesma área de $P$. glazioviana Engl. subsp. glazioviana, $P$. ciliata Mart. (Mapa 5) exibe maior restrição ecológica, pois está ausente nas florestas de restinga onde a outra espécie aparece com freqüência. Com distribuição ainda restrita, temos $P$. bahiensis Turcz. das restingas e "brejos" da Bahia, e a espécie próxima desta, $P$. andrade-limae Pirani, aparentemente confinada às florestas de restinga e tropical úmida da Paraíba a Alagoas (Mapa 8).

Com distribuição centrada no sul do Brasil (III), temos duas espécies de flores trímeras: $P$. parvifolia Engl., abundante nas florestas subtropicais, florestas de Araucaria e florestas do litoral paranaense, penetrando em São Paulo até o centro-sul de Minas Gerais (Mapa 8), e uma espécie muito próxima, P. excelsa Kuhlmann ex Pirani, restrita às florestas de Araucaria do Paraná e Santa Catarina (Mapa 8).

Ainda no grupo de distribuição restrita (2), temos $P$. oreadica Pirani, arbusto do Planalto Central, com 2 subespécies ocorrentes em manchas disjuntas de cerrados-de-chapada inclusas ou nos domínios dos cerrados (Goiás e DF) ou das caatingas (Bahia) (Mapa 4).

Com a distribuição geográfica conhecida muito restrita (Padrão 3, tab. 1), provavelmente representando micro-endemismos, temos $P$. ferrea Pirani $\&$ Thomas, endêmica dos afloramentos de canga férrica da Serra de Carajás (Pará, Mapa 4), P. campestris Rizz. \& Occh., das serras do Cabral e de Diamantina (Minas Gerais, Mapa 4), e $P$. grandifolia Engl., conhecida apenas de duas coleções antigas do Rio de Janeiro e recentemente recoletada (Mapa 4).

Dados resumidos sobre os principais habitats de cada espécie são apresentadas ainda na Tabela 1. Verifica-se que a amplitude ecológica é muito maior nas espécies de larga distribuição, enquanto as de área de ocorrência mais restrita ou ocupam habitats diversos ou têm preferências ecológicas mais específicas.

Em síntese da fitogeografia das Picramnia brasileiras, apresentam-se ainda as Tabelas 2 e 3 e o Mapa 9. Neste mapa, foram distintas 5 "regiões" do Brasil nas quais de maneira global concentram-se diferentes conjuntos de espécies: Amazônica (8 spp), centro e nordeste (7 spp), região costeira da $\mathrm{Pa}$ raíba a Alagoas (5 spp), costa da Bahia a São Paulo (7 spp) e Brasil Meridional (4 spp). Primeiramente constatamos que as maiores concentrações de espécies estão nas regiões amazônica, leste e central, porém nas duas primeiras a maioria dos táxons possui efetivamente centro de distribuição na área, enquanto no Brasil Central apenas 2 espécies constituem endemismos regionais (as 4 restantes aí ocorrem na verdade como extensões das áreas de ocorrência de táxons das 


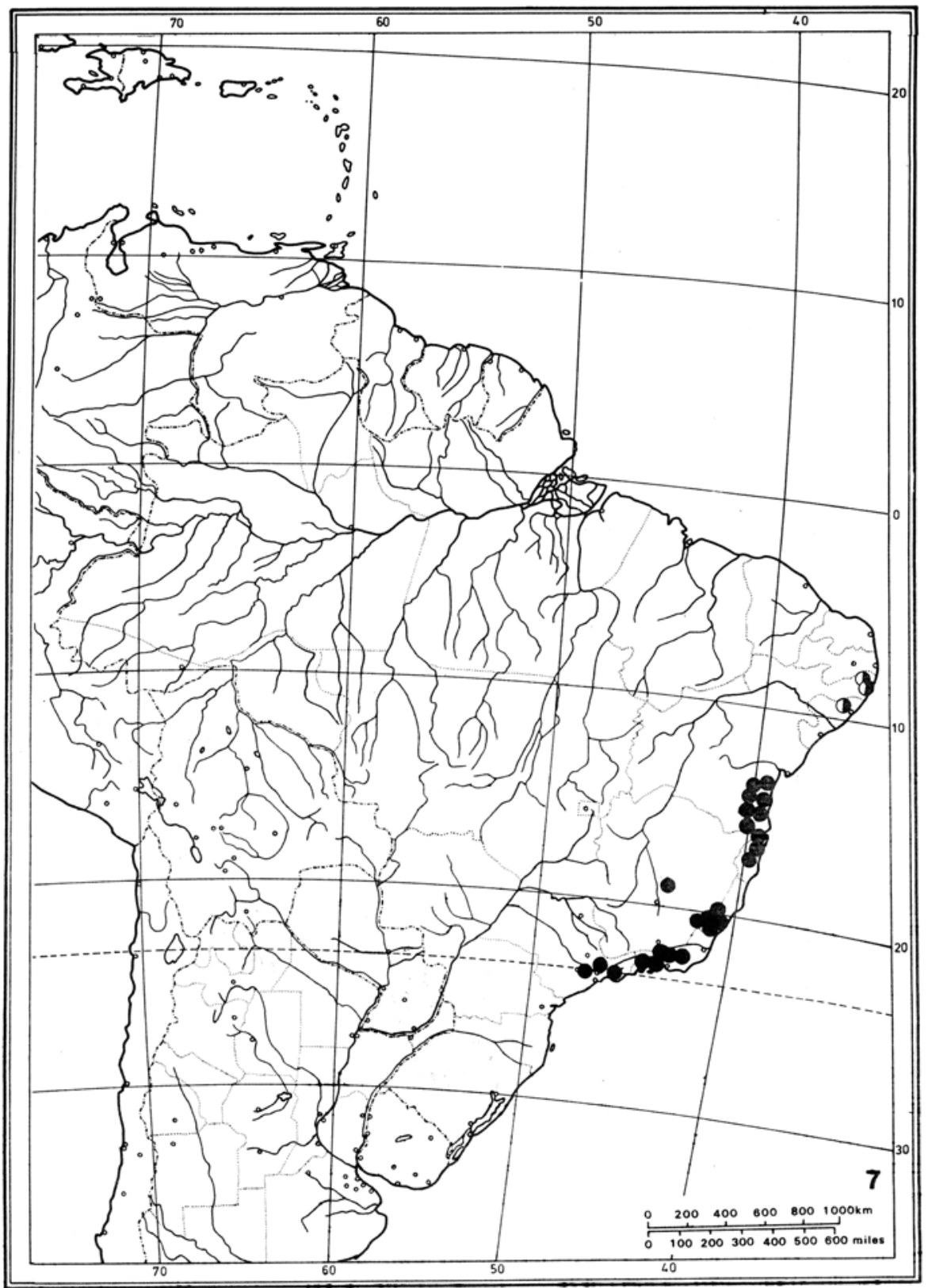

Mapa 7 - Distribuição geográfica de Picramnia glazioviana Engl. subsp. glazioviana (círculos negros) e subsp. amplifoliola Pirani (círculos semi-preenchidos). 


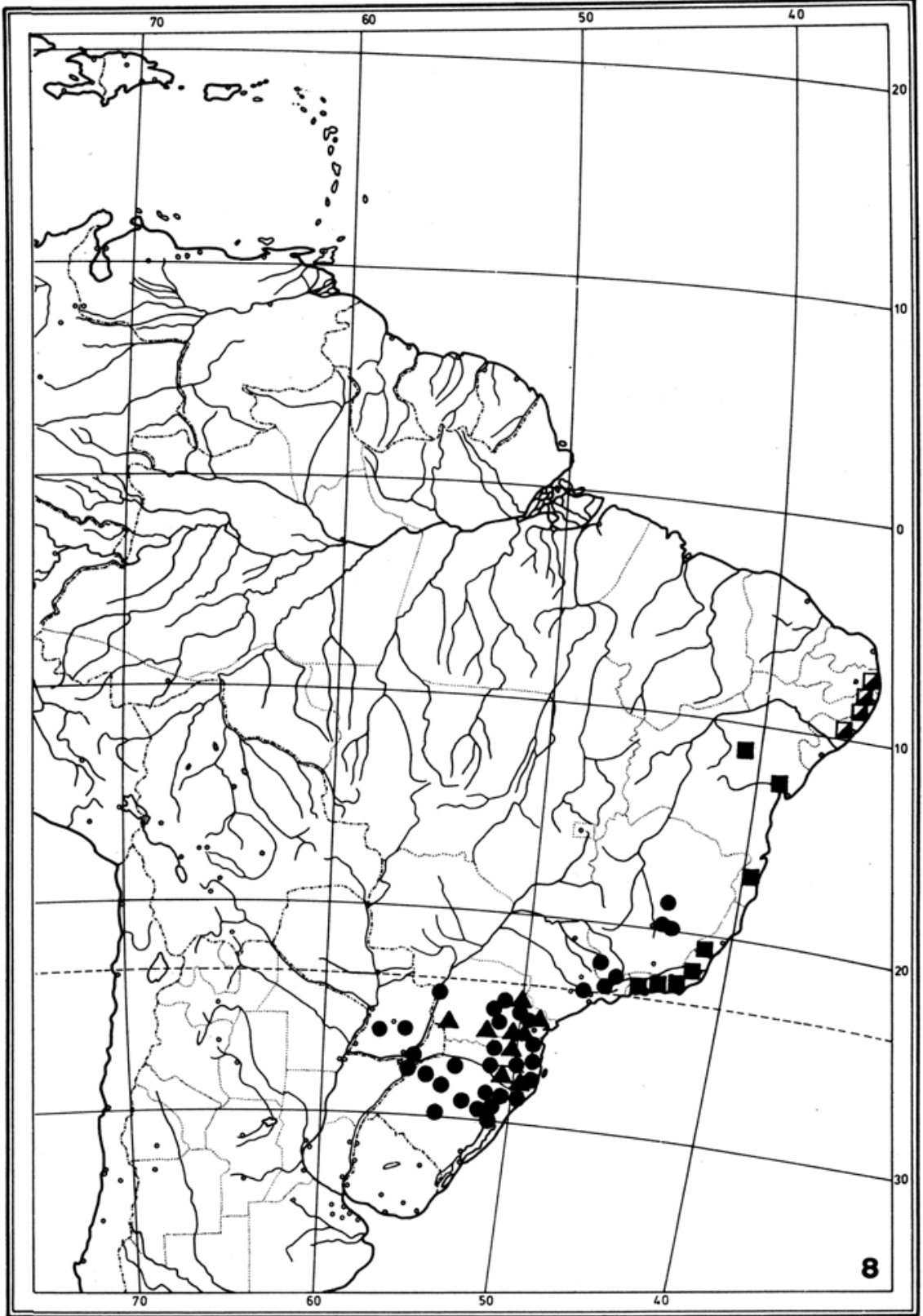

Mapa 8 - Distribuição geográfica de Picramnia andrade-limae Pirani (quadrados semi-preenchidos); $P$. bahiensis Turcz..(quadrados pretos); $P$. parvifolia Engl. (círculos) e $P$. excelsa Kuhlmann ex Pirani (triângulos). 


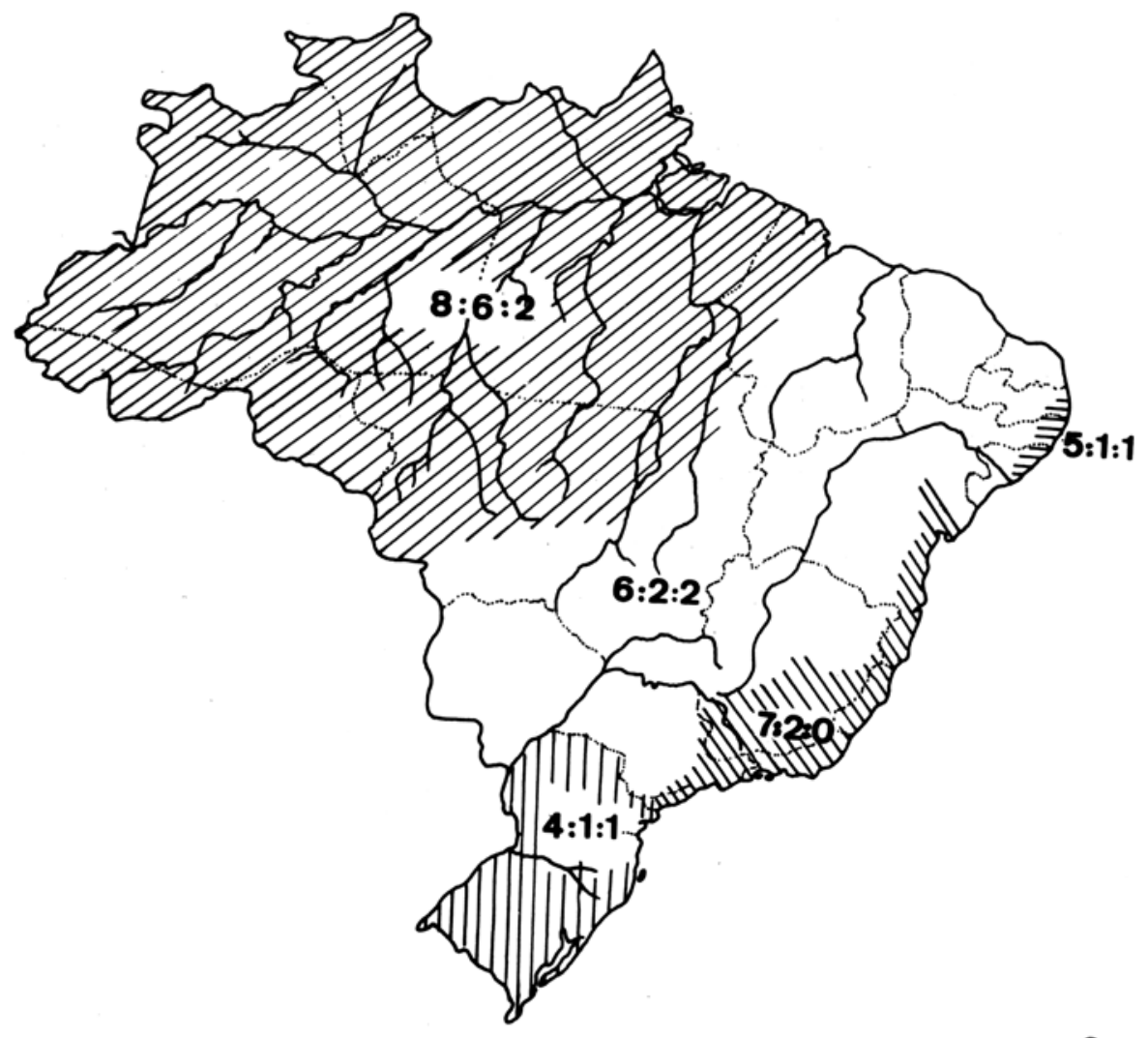

9
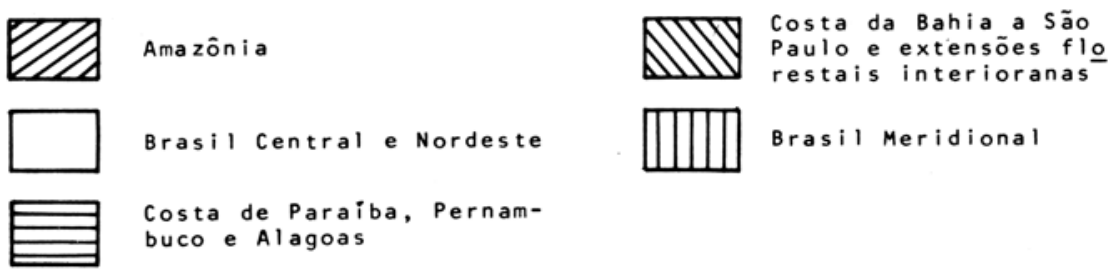

Mapa 9 - Distribuição geral das espécies de Picramnia no Brasil. As áreas hachudas representam "regiões" com diferentes conjuntos de espécies. Em cada área, a série numérica indica: total de spp. na área: spp. restritas, no Brasil, à área: spp. novas ou recentemente descritas. 


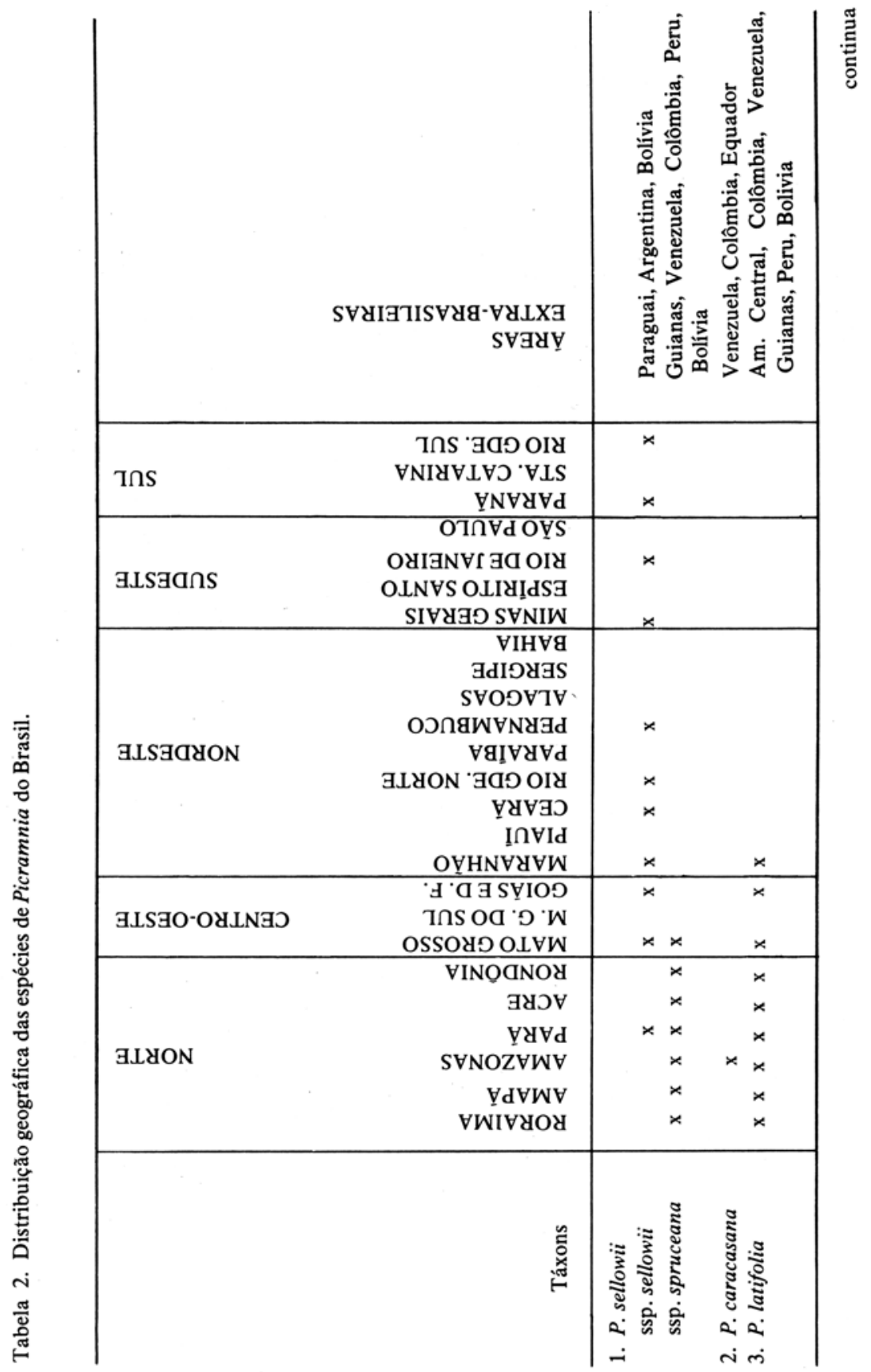




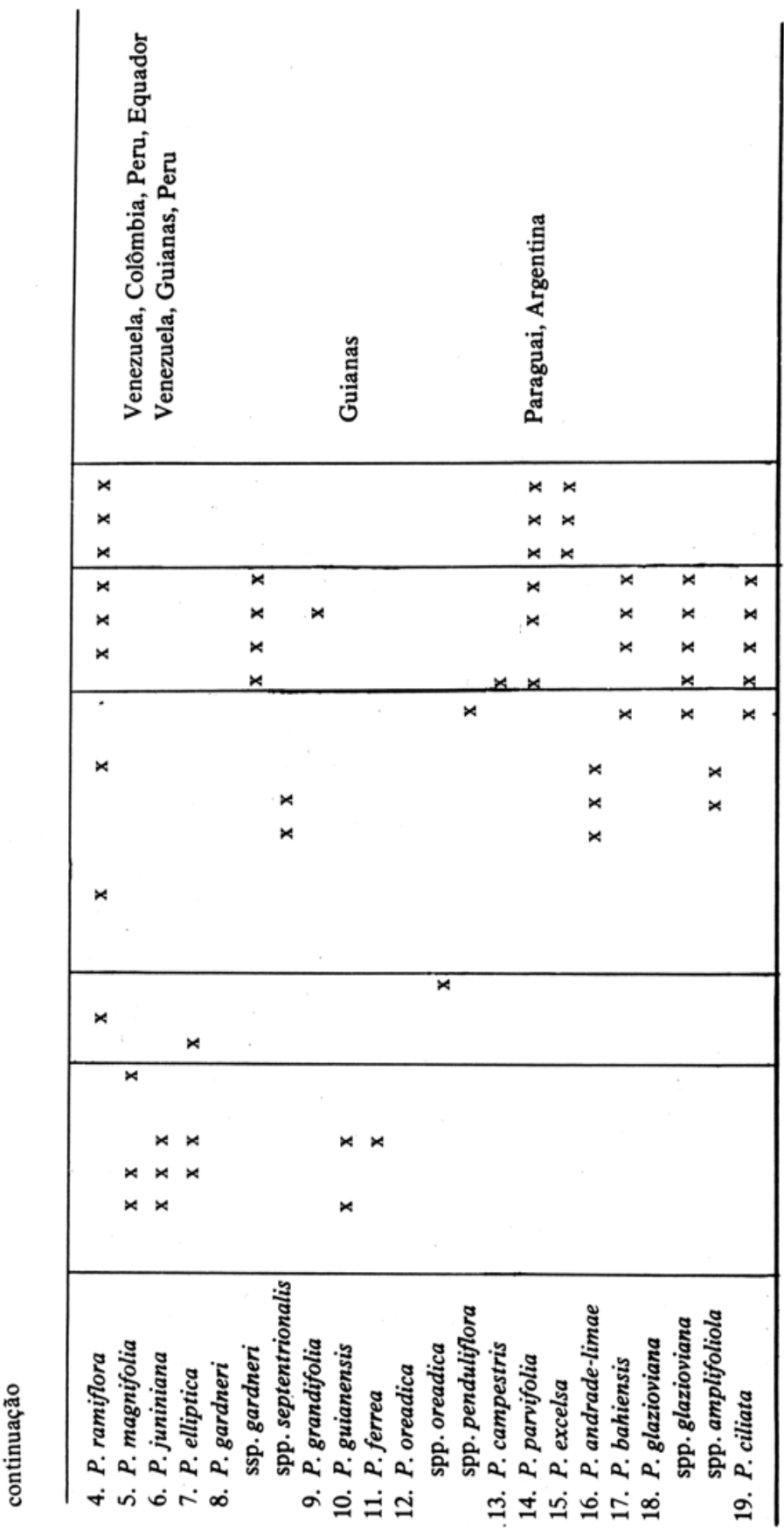


Tabela 3. Espécies brasileiras de Picramnia e suas respectivas espécies mais próximas.

\begin{tabular}{|c|c|c|}
\hline Espécie & Espécie(s) mais próxima(s) & Distribuição da espécie mais próxima \\
\hline $\begin{array}{l}\text { 1. P. sellowii } \\
\text { Planch. }\end{array}$ & P. pentrandra Sw. & $\begin{array}{l}\text { alopátrica (Antilhas e costa norte da Am. } \\
\text { do Sul) }\end{array}$ \\
\hline & P. caracasana & parcialmente simpátrica \\
\hline $\begin{array}{l}\text { 2. P. caracasana } \\
\text { Engl. }\end{array}$ & $P$. sellowii & parcialmente simpátrica \\
\hline $\begin{array}{l}\text { 3. P. latifolia } \\
\text { Tul. }\end{array}$ & P. ramiflora & alopátrica (Nordeste ao Sul do Brasil) \\
\hline $\begin{array}{l}\text { 4. P. ramiflora } \\
\text { Planch. }\end{array}$ & P. latifolia & $\begin{array}{l}\text { alopátrica (Am. Central ao norte e centro do } \\
\text { Brasil) }\end{array}$ \\
\hline $\begin{array}{l}\text { 5. P. magnifolia } \\
\text { Macbr. }\end{array}$ & P. latifolia & simpátrica \\
\hline 6. P. juniniana Macbr. & P. elliptica & parcialmente simpátrica \\
\hline $\begin{array}{l}\text { 7. P. elliptica } \\
\text { Pirani \& Thomas }\end{array}$ & P. juniniana & parcialmente simpátrica \\
\hline 8. P. gardneri Planch. & P. elliptica & alopátrica (AM, PA, MT) \\
\hline 9. P. grandifolia Engl. & P. gardneri & simpátrica \\
\hline $\begin{array}{l}\text { 10. P. guianensis } \\
\text { (Aubl.) Jansen-Jacobs }\end{array}$ & P. ferrea & alopátrica (Serra de Carajás, PA) \\
\hline $\begin{array}{l}\text { 11. P. ferrea } \\
\text { Pirani \& Thomas }\end{array}$ & P. guianensis & alopátrica (PA, AP, Guianas) \\
\hline 12. P. oreadica Pirani & P. campestris & alopátrica (MG) \\
\hline $\begin{array}{l}\text { 13. P. campestris } \\
\text { Rizz. \& Occh. }\end{array}$ & $P$. oreadica & alopátrica (DF, GO, BA) \\
\hline $\begin{array}{l}\text { 14. P. parvifolia } \\
\text { Engl. }\end{array}$ & P. excelsa & simpátrica \\
\hline $\begin{array}{l}\text { 15. P. excelsa Kuhlmann } \\
\text { ex. Pirani }\end{array}$ & P. parvifolia & simpátrica \\
\hline $\begin{array}{l}\text { 16. P. andrade-limae } \\
\text { Pirani }\end{array}$ & P. bahiensis & alopátrica (BA, ES, RJ) \\
\hline 17. P. bahiensis Turcz. & $\begin{array}{l}\text { P. andrade-limae } \\
\text { P. parvifolia }\end{array}$ & $\begin{array}{l}\text { alopátrica (PB, PE, } \mathrm{AL}) \\
\text { alopátrica (MG ao RS, Paraguai, Argentina) }\end{array}$ \\
\hline $\begin{array}{l}\text { 18. P. glazioviana Engl. } \\
\text { 19. P. ciliata Mart. }\end{array}$ & $\begin{array}{l}P . \text { ciliata } \\
P . \text { glazioviana }\end{array}$ & $\begin{array}{l}\text { simpátrica } \\
\text { simpátrica }\end{array}$ \\
\hline
\end{tabular}

regiões vizinhas). Além disso, em que pese a possibilidade de ser essa área central menos coberta por coletas, ainda assim nos parece muito evidente a menor expressividade no Brasil Central das populações de espécies como $P$. ramiflora e $\boldsymbol{P}$. glazioviana (com centro na região Leste-Sudeste) e $\boldsymbol{P}$. parvifolia (centrada no Brasil Meridional) ou ainda $P$. latifolia (basicamente amazônica). $O$ único táxon de ampla distribuição que exibe grande expressão também no Brasil Central e Nordeste é $P$. sellowii subsp. sellowii. Caracteristicamente, esta entidade estende-se da Argentina e Paraguai pelas matas-de-galeria e florestas de planalto do Brasil Central até o Nordeste, onde ocorre também nos "brejos" das 
serras e na floresta úmida litorânea, embora seja substituída por outras espécies nas florestas úmidas da Bahia e Sudeste ao Sul (ver Mapa 2).

Posto isso, podemos concluir que os principais centros de diversidade genética de Picramnia no Brasil são a Amazônia e a costa leste. Analisando o Mapa 2 em consonância com a Tabela 2, constatamos que se tratarmos globalmente as duas áreas de floresta aṭântica e suas formas transicionais para as florestas do interior, teremos uma área com 9 espécies das quais 7 têm o centro de distribuição na própria área, o que implicaria estar aí o maior centro de diversidade de Picramnia no país.

Tomando os diversos padrões de distribuição estudados e as relações taxonômicas mais estreitas de cada espécie (relacionadas na Tabela 3), poderemos fazer conjecturas acerca da história destes táxons. Analisando a Tabela 3, poderemos sumarizar assim os números de espécies brasileiras com suas relativas espécies mais próximas:

\begin{tabular}{cl}
\hline No de espécies do Brasil & \multicolumn{1}{c}{ Distribuição da espécie mais afim } \\
\hline 9 & Amazônia (alopátrica ou simpátrica) \\
7 & Brasil Oriental (alopátrica ou simpátrica) \\
2 & Brasil Central (alopátrica) \\
2 & Brasil Meridional (simpátrica) \\
\hline
\end{tabular}

A primeira constatação é a de que o maior número de ligações estreitas de parentesco se estabelece com táxons da Amazônia e da costa leste, o que é apenas reflexo das conclusões expostas anteriormente sobre os dois principais centros de diversidade do gênero e acerca da natureza da maioria das espécies que ocupam o Planalto Central e o Nordeste.

Consideremos agora casos específicos, baseados na Tabela 3: $P$. ramiflora e $P$. gardneri, centradas na floresta atlântica, têm sua afinidade mais estreita respectivamente com $P$. latifolia e $P$. elliptica, ambas basicamente amazônicas. Em adição, temos $P$. sellowii que é amplamente distribuída na Amazônia e alcança também a floresta atlântica pelo menos no Nordeste. Tais fatos fornecem então evidências para a suposta ligação que teria existido no passado entre a hiléia e a floresta pluvial costeira, já reportada por vários autores. AndradeLima (1953, 1982) discutiu e listou mais de 60 espécies de famílias diversas comuns a estas duas áreas, o que foi corroborado com vários outros exemplos citados por Rizzini (1979) e ainda outros em Chrysobalanaceae por Prance (1979a, 1982a), e mais recentemente em Parkia (Leguminosae) por Hopkins (1986). Em Picramnia os parentescos citados para táxons dessas duas áreas envolvem entidades que aparentemente compõem pares vicariantes: $P$. latifolia$P$. ramiflora; $P$. sellowii subsp. sellowii - subsp. spruceana.

A floresta pluvial atlântica tem sido considerada como um "refúgio" (segundo a "teoria dos refúgios", cujas bases principais estão discutidas em Haffer 
1982) por geomorfologistas (Ab'Saber 1982), zoólogos e botânicos (e.g. Brown 1982 para Lepidoptera; Prance 1979a, 1982a, b, para angiospermas de diversas famílias). Esta área deve ter permanecido relativamente estável e úmida durante os climas mais secos do Pleistoceno, e provavelmente o seu isolamento precedeu de muito a glaciação desse período. Assim, autores diversos postulam a existência de conexão entre a floresta amazônica com a floresta atlântica durante o Terciário (Rizzini 1967 e Simpson 1969 apud Prance 1979a, AndradeLima 1953, 1982; Langenheim et al. 1973; Rizzini 1979; Prance 1982a, b). Os dados de algumas Picramnia também fornecem evidências para esta hipótese.

Tratando ainda das espécies centradas na floresta atlântica, os dados sumarizados na Tabela 2, indicando a distribuição de cada espécie estado a estado, revelam que afora algumas espécies que se estendem em ampla distribuição dentro e/ou fora desta área ( $P$. sellowii, $P$. ramiflora), várias são bem restritas. Destaca-se $P$. andrade-limae, endêmica da Paraíba a Alagoas, área à qual também estão confinadas as novas subespécies de $P$. glazioviana e $P$. gardneri propostas por Pirani $(1989,1990)$. Na verdade, são 3 as áreas de refúgio distintas na floresta atlântica, primeiro por Brown (1976) e aceitas por Prance (1982a, B): Paraíba-Pernambuco-Alagoas; sul da Bahia até o Rio Doce; sul do Espírito Santo até São Paulo. A existência de uma lacuna de distribuição ao nível do Rio Doce evidenciada por Prance (1979a), e por ele explicada com base em diferenças climáticas atuais (pluviosidade muito maior ao norte do Rio Doce), não é respeitada por espécies como $P$. ciliata, $P$. bahiensis e $P$. glazioviana, mas $P$. gardneri tem suas duas subespécies restritas aos dois refúgios extremos da floresta costeira e está ausente no mediano (v. Mapa 6).

Assim, segundo Prance (1979a, 1982a, b) as florestas da costa leste brasileira constituem ainda refúgios contemporâneos funcionais, porque muitas espécies não puderam mais se reexpandir. Em Picramnia algumas espécies da floresta atlântica ocorrem também nas extensões de florestas que penetram no Planalto Central, como $P$. glazioviana, $P$. ciliata e $P$. gardneri, ou nos "brejos" das serras e chapadas dos domínios das caatingas ( $P$. bahiensis, $P$. ramiflora, $P$. sellowii). A baixa freqüência destas espécies no interior, inferida pelas poucas coletas, pode ser reflexo de mau conhecimento da flora, mas acreditamos ser provavelmente decorrência do caráter remanescente de táxons de distribuição maior no passado. O caráter relictual dos "brejos" do Nordeste, ilhas nas áreas predominantemente xéricas, já foi ressaltado por Andrade-Lima (1982) e Prance (1982b); este último autor comenta a presença de espécies amazônicas e sulinas nos "brejos", indicando que estes constituem "a most interesting relict with a mixture of isolated species".

Interessa-nos ainda dentro desta abordagem a distribuição de $P$. parvifolia, espécie centrada no Brasil Meridional mas que alcança o interior de Minas Gerais. Sua área de ocorrência (Mapa 9) coincide com a distribuição das formações com Araucaria durante 13.000 a 18.000 anos atrás segundo Ab'Saber (1977). Atualmente $P$. parvifolia é freqüente nas matas subtropicais, ausente na 
floresta atlântica do Sudeste e Leste, e sua presença mais rara nas florestas serranas do interior de Minas deve ser entendida como relictual. A mesma área do interior mineiro conta também com a presença de $P$. glazioviana e $P$. ciliata, francamente atlânticas, demonstrando mais uma vez o "caráter misto" dessas florestas mediterrâneas, que na sua composição contam com elementos de origens diversas.

\section{Relacionamento entre padrõres de variabilidade e de distribuição geográfica}

Considerando agora a diferenciação interespecífica, o grau de variabilidade interna nas espécies e sua distribuição geográfica e ecologia, agrupamos as espécies brasileiras de Picramnia segundo categorias propostas em estudos anteriores para outras famílias de dicotiledôneas tropicais, principalmente White (1978) em Ebenaceae, Pennington (1981) em Meliaceae e Prance (1988) em Chrysobalanaceae, Caryocaraceae, Dichapetalaceae e Lecythidaceae. Distinguimos em Picramnia as categorias seguintes (que não são mutuamente exclusivas):

\section{a) Espécies monotípicas, taxonomicamente isoladas}

Incluem-se aqui espécies morfologicamente bem distintas de todas as outras por vários caracteres diagnósticos. A sua variabilidade interna pode ser pequena a grande, mas nunca é suficiente para reconhecimento de subespécies. Com variabilidade intra-específica pequena temos $P$. campestris, com distribuição e amplitude ecológica reduzidas, enquanto $P$. elliptica, $P$. juniniana e $P$. magnifolia têm área geográfica considerável e variabilidade entre populações relativamente apreciável mas ainda assim pequena.

\section{b) Pares ou grupos de espécies proximamente relacionadas}

Nesta categoria são incluídas espécies separáveis por poucos caracteres diagnósticos ou pela variação combinada de vários caracteres diferenciais (sensu White 1978). Há duas possibilidades: os membros do grupo (ou par) são alopátricos, não se sabendo se são isolados reprodutivamente, correspondendo às "super-espécies" da zoologia (Mayr 1942), ou são parcial a completamente simpátricos, caso em que as suas diferenças morfológicas são suportadas por isolamentos reprodutivo e/ou ausência de intermediários.

Como táxons alopátricos, temos os seguintes exemplos: $P$. latifolia (América Central e Ámazônia até Mato Grosso, Goiás e Maranhão) e $P$. ramiflora (costa nordeste - Ceará - até sul do Brasil, penetrando até o Mato Grosso do Sul); $P$. bahiensis (do Rio de Janeiro até a Bahia) e $P$. andrade-limae (de Ala- 
goas à Paraíba); $P$. pentandra (Antilhas, Flórida e costa da Venezuela) e $P$. sellowii (América do Sul); e o grupo de espécies relacionadas a $P$. oreadica (DF, GO e BA), incluindo $P$. campestris (MG), $P$. ferrea (PA) e $P$. guianensis (AP, PA e Guianas).

Os componentes das "super-espécies" (os três primeiros pares supramencionados) ou do grupo intimamente relacionado (de $P$. oreadica) podem apresentar variabilidade intra-específica muito grande. Isso é notório em $P$. ramiflora, $P$. guianensis e principalmente em $P$. latifolia; em $P$. oreadica e $P$. sellowii a variabilidade é suficiente para sua inclusão também na categoria de "espécie politípica" (item c).

Com relação aos grupos onde há simpatria, geralmente pouco se sabe das condições ou meios de manutenção do isolamento das espécies componentes. Em alguns casos, a assincronia fenológica pode estar atuando consistentemente nesse sentido, como parece acontecer em $P$. parvifolia (MG até RS, Argentina e Paraguai) e $P$. excelsa (PR e SC), que coabitam uma mesma floresta mas têm períodos de florescimento bem separados ao longo do ano. Noutros casos há alguma evidência de tendência a preferências ecológicas diferenciais; por exemplo, $P$. ciliata e $P$. glazioviana ocorrem com grande superposição de áreas de São Paulo ao sul da Bahia, ambas penetrando até o interior de Minas Gerais, mas ao menos nas florestas visitadas (SP, ES, MG e BA) não encontramos populações convivendo próximas, e $P$. ciliata está ausente nas florestas de restingas de ES e BA, onde encontramos numerosas populações de $P$. glazioviana No csao de $P$. sellowii e $P$. caracasana, que têm simpatria em apenas pequenas áreas da Amazônia, talvez se notem também diferenças ecológicas. Um último para a ser aqui mencionado é $P$. guardneri (Nordeste até SP) e $P$. grandifolia (endêmica do RJ e pobremente conhecida).

Assim, a distribuição geográfica dos componentes destes pares ou grupos pode muitas vezes indicar que o isolamento geográfico empenhou ou tem empenhado papel importante na sua origem. Isso é obviamente válido para os táxons alopátricos anteriormente citados, mas mesmo no caso de $P$. sellowii- $P$. caracasana, atualmente parcialmente simpátricas, poderíamos supor uma situação de isolamento nos períodos mais secos do Pleistoceno em "refúgios" separados, que levou à acumulação de diferenciações suficientes para a sua manutenção como táxons distintos mesmo depois da confluência dos refúgios amazônicos, em consonância com as evidências fitogeográficas propostas nos trabalhos discutidos anteriormente (e.g. Prance 1979a, 1982a, b).

\section{c) Espécies politípicas}

São espécies onde uma alta variabilidade morfológica está razoavelmente bem correlacionada a diferentes áreas geográficas (ou ecológicas), podendo ser subdivididas em subespécies. Segundo Prance (1988), as “subespécies geográ- 
ficas" correspondem aos táxons infra-específicos de "maior valor na atual conjuntura de nosso conhecimento sobre a flora amazônica", acrescentando ainda: "As diferenciações entre as subespécies se manifestam em caracteres filogeneticamente menos importantes e que não justificam a separação a nível de espécie. Provavelmente, existe algum intercâmbio genético entre as subespécies onde suas distribuições geográficas se sobrepõem".

As espécies politípicas reconhecidas em Picramnia são geralmente membros de pares ou grupos relacionados (categoria b): $P$. sellowii, amplamente distribuída na América do Sul, tem duas subespécies, subsp. sellowii e subsp. spruceana (Engl.) Pirani (Mapa 2); $P$. oreadica, do Brasil Central, tem a subespécie típica em Goiás, e a subsp. penduliflora na Bahia; $P$. glazioviana e $P$. gardneri não são próximas mas exibem padrões semelhantes: ambas com uma subespécie nordestina disjunta da subespécie típica restrita ao Sul e Sudeste (Mapas 6 e 7).

Enquanto nos três últimos exemplos ( $P$. glazioviana, $P$. gardneri e $P$. oreadica) há evidente separação geográfica entre as subespécies, em $P$. sellowii ocorre muito contato entre elas, com ocorrência de formas mais ou menos intermediárias.

No tratamento apresentado recentemente por Thomas (1988), aparece uma outra espécie politípica: $P$. antid $\_m a$ Sw. (com três subespécies, todas extrabrasileiras).

\section{d) Espécies complexas (segundò Pennington 1981) \\ ou "ochlo-espécies" (de White 1978 e Prance 1982a, 1988)}

São espécies caracterizadas pela larga distribuição geográfica e cujos complexos padrões de variabilidade estão apenas parcialmente correlacionados com a geografia e ecologia, porquanto são encontradas em condiçð̃es climáticas diversas e em vários tipos de comunidades vegetais. Incluem-se aqui $P$. latifolia e $P$. ramiflora, que são também espécies proximamente relacionadas (categoria b) mas alopátricas. Caracteristicamente, observa-se nestas espécies que enquanto uma população pode conter duas "formas" aparentemente distintas (isoladas reprodutivamente?), as formas intermediárias entre elas vão ser encontradas em áreas distintas da desta primeira população.

\section{Conclusão}

Finalmente, consideremos a distribuição geográfica global e história evolutiva do gếnero. É interessante notar que, assim como nos gêneros Alvaradoa, Castela e Picrasma, que são disjuntos na América Central ou norte da América do Sul e Brasil Meridional-Argentina-Bolívia, também em Picramnia vamos 
encontrar as espécies com flores trímeras representadas nos polos América Central-norte da América do Sul (costa da Venezuela) e Brasil Oriental-Meridional, estando totalmente ausentes na Amazônia e região subandina (v. Mapa 1). Cronquist (1944a, d), nas revisões dos três gêneros supracitados, não discutiu o padrão disjunto nem correlacionou-o com a história de especiação ou migração nestes táxons. No caso de Picramnia, a trimeria, aqui encarada como um caráter derivado, pode ser indício de origem filogenética comum para os dois conjuntos de espécies que a apresentam (atualmente disjuntos), ou pode ter sido alcançada independentemente por cada um deles, ou seja, pode representar um caso de paralelismo. Atestando a primeira hipótese, temos as evidências de uma série de outros táxons que poderiam ter migrado do norte via subandina até as florestas subtropicais da Argentina e Sul do Brasil. Esta hipótese é defendida por Smith (1962), Rizzini (1979) e Steyermark (1982), que cita como exemplos os gêneros Clethra (Clethraceae), Weinmannia (Cunoniaceae), Podocarpus (Podocarpaceae), Drymis (Winteraceae) e Hedyosmum (Chloranthaceae), o que foi também admitido por Gentry (1982) e Giulietti \& Pirani (1988). Nas Picramnia trímeras, contudo, não há evidência atual de ligação via-flancos orientais andinos, e a presença de inflorescências em tirsos simples (racemiformes) em várias espécies do grupo disjunto ao norte (e.g. P. antidesma Sw., P. hirsuta W. Thomas, $P$. teapensis Tul. e $P$. polyantha (Benth.) Planch.), caráter totalmente ausente no grupo disjunto sulino (sempre com diplo ou pleiotirsos) provavelmente constitua evidência de paralelismo na trimeria ("inside paralelism" de Brundin 1981).

De tudo que vimos, as principais conclusões ou generalizações a serem obtidas são as seguintes. Sendo Picramnia um gênero exclusivamente neotropical, provavelmente teve origem relativamente recente, após a separação dos continentes gondwânicos, que se deu no Cretáceo. Como mostrou Pirani (1989), apesar da ampla área de distribuição geográfica, o gênero não alcançou ainda uma diversificação morfológica profunda, ao contrário, possui uma certa unìformidade generalizada nos vários caracteres, cujas divergências interespecíficas representam pouco mais que variações em torno de um tema central muito flexível, o que ainda dificulta o entendimento da hierarquia filética no gênero.

\section{Referências bibliográficas}

AB'SABER, A. N. 1977. Espaços ocupados pela expansão dos climas secos na América do Sul, por ocasião dos períodos glaciais quaternários. Paleoclimas, Univ. S. Paulo 3: 1-19.

AB'SABER, A. N. 1982. The paleoclimate and paleoecology of Brazilian Amazonia. In: PRANCE, G. T. (ed.). Biological diversification in the tropics. Columbia University Press, New York, p. 41-59. 
ANDRADE-LIMA, D. 1953. Notas sobre a dispersão de algumas espécies vegetais no Brasil. An.Soc. Biol. Pernambuco 11(1): 25-49.

ANDRADE-LIMA, D. 1966. Vegetação. In: Atlas Nacional do Brasil, IBGE.

ANDRADE-LIMA, D. 1982. Present-day forest refuges in Northeastern Brazil. In: PRANCE, G. T. (ed.). Biological diversification in the tropics. Columbia University Press, New York, p. 245-251.

BROWN, K. S., Jr. 1976. Geographical patterns of evolution in neotropical Lepidoptera. Systematics and derivation of known and new Heliconinii (Nymphalidae: Nymphalinae). J. Ent. (B) 44(3): 201-242.

BROWN, K. S., Jr. 1982. Paleocology and regional patterns of evolution in neotropical forest butterflies. In: PRANCE, G. T. (ed.) Biological diversification in the tropics. Columbia University Press, New York, p. 255-308.

BRUNDIN, L. Z. 1981. Croizat's Panbiogeography versus phylogenetic biogeography. In: NELSON, G. \& ROSEN, D. E. (eds.). Vicariance biogeograph - a critique. Columbia University Press, New York, p. 94-150.

CROAT, T. 1978. Flora of Barro Colorado Island. Stanford University Press, Stanford. CRONQUIST, A. 1944a. Studies in the Simaroubaceae I. The genus Castela. J. Arnold Arb. 25(1): 122-128.

CRONQUIST, A. 1944b. Studies in the Simaroubaceae IV. Resume of the American genera. Brittonia 5(2): 128-147.

DUCKE, A. \& BLACK, G. A. 1953. Phytogeographical notes on the Brazilian Amazon. An. Acad. brasil. Cienc. 24(1): 1-46.

ENGLER, A. 1874. Simaroubaceae. In: MARTIUS, C. F. P.; EICHLER, A. G. \& URBAN, I. (eds.). Flora Brasiliensis 12(2): 197-248.

ENGLER, A. 1931. Simaroubaceae. In: ENGLER, A. \& PRANTL, K. (eds.) Die natürlichen Pflanzenfamilien ed. 2, 19a:359-405.

GENTRY, A. H. 1982. Neotropical floristic diversity: phytogeographical connections between Central and South America, Pleistocene climatic fluctuations, or an accident of Andean orogeny? Ann. Missouri Bot. Gard. 69(3): 557-593.

GIULIETTI, A. M. \& PIRANI, J. R. 1988. Patterns of geographic distribution of some plant species from the Espinhaço Range, Minas Gerais and Bahia, Brazil. In: VANZOLINI, P. E. \& HEYER, W. R. (eds.) Proceedings of a workshop on neotropical distribution patterns. Academia Brasileira de Ciências, Rio de Janeiro, p. 39-69.

HAFFER, J. 1982. General aspects of the Refuge Theory. In: PRANCE, G. T. (ed.). Biological diversification in the tropics. Columbia University Press, New York, p. 6-24.

HOPKINS, H. C. F. 1986. Parkia (Leguminosae: Mimosoideae). Flora Neotropica 43: 1-124.

HUECK, K. 1972. As florestas da América do Sul. Ed. Universidade de Brasília, Ed. Polígono, São Paulo.

LANGENHEIM, J. H.; LEE, J. T. \& MARTIN, S. S. 1973. An evolutionary and ecological perspective of Amazonia Hylaea species of Hymeneae (Leguminosae-Caesalpinioideae). Acta Amaz. 3(1): 5-38.

LOMBARDO, A. 1964. Flora arborea y arborescente del Uruguay. Concejo Departamental de Montevideo, Montevideo. 
MAYR, E. 1942. Systematics and the origin of species. Columbia University Press, New York.

PENNINGTON, T. D. 1981. Meliaceae. Flora Neotropica 28: 1-470.

PIRANI, J. R. 1988. Uma nova espécie de Picramnia e notas sobre Picramnia campestris Rizz. \& Occh. (Simaroubaceae). Bolm Botânica, Univ. S. Paulo 10: 7-13.

PIRANI, J. R. \& THOMAS, W. W. 1988. Duas novas espécies de Picramnia (Simaroubaceae) para a flora do norte do Brasil. Bolm. Mus. Par. Emílio Goeldi 20: 179-202.

PIRANI, J. R. 1989. Revisão taxonômica de Picramnia Sw. (Simaroubaceae) no Brasil. Tese de doutorado, Univ. S. Paulo, São Paulo.

PIRANI, J. R. 1990. As espécies de Picramnia do Brasil: uma sinopse. Bolm. Botânica, Univ. S. Paulo 12 (no prelo).

PIRES, J. M. 1973. Tipos de vegetação da Amazônia. Publ. Avuls. Mus. Par. Emílio Goeldi 20: 179-202.

PRANCE, G. T. 1975. Flora e vegetação. In: GOODLAND, R. J. A. \& IRWIN, H. S. (eds.) A selva amazônica: do inferno verde ao deserto vermelho? Livraria Itatiaia Editora, EDUSP, Belo Horizonte.

PRANCE, G. T. 1979a. The taxonomy and phytogeography of the Chrysobalanaceae of the Atlantic coastal forests of Brazil. Revta. brasil. Bot. 2(1): 19-39.

PRANCE, G. T. 1979b. Notes on the vegetation of Amazonia III. The terminology of amazonian forest types subject to inundation. Brittonia 31(1): 26-38.

PRANCE, G. T. 1982a. Forest refuges: evidence from woody angiosperms. In: PRANCE, G. T. (ed.). Biological diversification in the tropics. Columbia University Press, New York, p. 137-158.

PRANCE, G. T. 1982b. A review of the phytogeographic evidences for Pleistocene climate changes in the Neotropics. Ann. Missouri Bot. Gard. 69(4): 594-624.

PRANCE, G. T. 1988. Padrões de distribuição e especiação em Chrysobalanaceae e outras famílias de plantas amazônicas. Acta bot. bras. 1(2): 1-25 (supl.).

RIZZINI, C. T. 1979. Tratado de fitogeografia do Brasil. vol. 2. Editora HUCITEC, EDUSP, São Paulo.

SCHOLZ, H. 1964. Reihe Rutales. In: MELCHIOR, H. (ed.). A. Engler's Syllabus der Pflanzenfamilien ed. 12, vol. 2. Gebrüder Borntraeger, Berlin, p. 262-277.

SMITH, L. B. 1962. Origins of the flora of southern Brazil. Contr. United States Nat. Herb. 35(3): 215-249.

STEYERMARK, J. A. 1982. Relationships of some Venezuelan forest refuges with lowland tropical floras. In: PRANCE, G. T. (ed.). Biological diversification in the tropics. Columbia University Press, New York, p. 182-220.

THOMAS, W. W. 1988. A conspectus of Mexican and Central American Picramnia (Simaroubaceae). Brittonia 40(1): 89-105.

WHITE, F. 1978. The taxonomy, ecology and chorology of African Ebenaceae. 1. The Guineo-Congolian species. Bull. Jard. Bot. Nat. Belg. 48(3/4): 245-358. 